\title{
Modeling of the Interaction of Flavanoids with GABA (A) Receptor Using PRECLAV (Property-Evaluation by Class Variables)
}

\author{
Vijay K. Agrawal ${ }^{1}$, Basheerulla Shaik ${ }^{1}$, Padmakar V. Khadikar ${ }^{1}$, Shalini Singh ${ }^{2}$ \\ ${ }^{1}$ Department of Applied Sciences, National Institute of Technical Teachers' Training \& Research, Bhopal, India; ${ }^{2}$ Depatment of \\ Chemistry, Bareily College, Bareily, India. \\ Email: basheerulla.81@gmail.com, pvkhadikar@rediffmail.com, shalinisingh_15@yahoo.com, apsvka@yahoo.co.in
}

Received April 28 ${ }^{\text {th }}, 2011$; revised August $17^{\text {th }}, 2011$; accepted September $20^{\text {th }}, 2011$.

\begin{abstract}
Quantitative Structure-Activity Relationship (2D-QSAR) models for binding affinity constants $\left(\log K_{i}\right)$ of 78 flavanoid ligands towards the benzodiazepine site of GABA $(A)$ receptor complex were estimated using the PRECLAV (Property-Evaluation by Class Variables) program. The best MLR equation with nine PRECLAV descriptors has $R^{2}=0.843$ and $R_{C}^{2}=0.782$. Attempt is also made for obtaining 2D-QSAR model using NCSS software. The comparison of the results indicated that the PRECLAV method is very efficient in detecting structure-activity correlation with good predictive power.
\end{abstract}

Keywords: PRECLAV, NCSS, Regression Analysis, Cross-Validation, GABA, Flavanoids

\section{Introduction}

During the last two decades quantitative structure-activity relationship (2D-QSAR) models have gained extensive recognition in drug design [1]. The widespread use of 2D-QSAR models come from the development of novel structural descriptors and statistical equations relating activity with chemical structure. The main hypothesis in the 2D-QSAR approach is that all biological activity of a chemical substance is statistically related to its molecular structure. The PRECLAV program uses the atom in the common skelton to compute bond and field (grid) descriptors $[2,3]$. The PRECLAV program computes five classes of structural descriptors: Constitutional, topological indices, molecular graph invariants, geometrical, quantum bond indices and field (grid) descriptors [2-4].

All molecules are aligned by superimposing the common atom before generating the multiple linear regression models; PRECLAV makes a descriptor selection by discarding those descriptors that are poorly correlated with the investigated activity.

During last decade more than 400 chemically unique flavonoids (phenyl-benzopyrans) have been isolated from vascular plants and many of them are used as tranquiliz- ers in folkloric medicine. Such type of compounds are important constituents of the human diet, being derived largely from fruits and vegetables, nuts, seeds, stems and flowers and thus constitute one of the important classes of the metabolites. Some of the compounds from flavones family exhibit a potent in vivo anxiolitic activity, and do not involve unwanted side effect. As a result of this several attempts have been made to generate synthetic flavones derivatives with higher affinities for the GABA (A) receptor [5-10]. Subsequently, attempts were also made to establish quantitative structure-activity relationship so as to establish a 2D-QSAR model for inhibition of GABA (A) receptor that could serve as a guide for the rational design of further potent and selective inhibition having the flavones backbone [11-13]. One such attempt was recently made by Duchowiz and co workers [14-16]. They have proposed the best linear model for a set of 70 flavones and found that the best model involves four correlating descriptors with statistical quality given by $\mathrm{R}^{2}=0.7174, \mathrm{Se}=0.580, \mathrm{R}_{\mathrm{LOO}}^{2}=0.6757, \mathrm{~S}_{\mathrm{LOO}}=$ 0.622 .

It was observed that out of several available software's such as COMFA [17], CORBA [18], OASIS [19], CODESSA [20], TSAR [21], PRECLAV [2,3], etc. The PRECLAV software is very efficient in detecting struc- 
ture-activity relationship with good predictive power. This has prompted us to use PRECLAV program for investigating GABA (A) receptor binding and to compare the findings with those obtained using NCSS software.

\section{Database and Modeling}

The data base used as input by PRECLAV consists of 78 flavoniods presented in Table 1 together with their log $\mathrm{K}_{\mathrm{i}}(\mu \mathrm{M})$ values [14]. The chemical structures were generated with Hyper Chem. [22], geometry optimization was performed with MOPAC [23] and the QSAR models were computed with PRECLAV $[2,3]$. MOPAC 7 output files are used by PRECLAV [2,3] program to compute PRECLAV descriptors for generating multiple linear regression models. Before such generation of the models PRECLAV software makes a descriptor selection by discarding those descriptors that are poorly correlated with the investigated activity. The following descriptors were generated in the present case:

\section{Notations of the Structural Descriptors Generated by PRECLAV}

1) MATS2p: Moran autocorrelation-lag $2 /$ weighted by atomic polarizabilities (2-D autocorrelation indices) Dragon Descriptor.

2) OXX: presence of Oxygen. Maximum charge for $O$ atom (at parabolic region) PRECLAV Descriptor.

3) NGS: area of negative charged surface/molecular surface area ratio (at parabolic region) PRECLAV Descriptor.

4) HBA: Capability to form.

5) Hydrogen bonded (function No. 1) (at parabolic region) PRECLAV Descriptor.

6) VLS: volume of circumscribed sphere (at parabolic region) PRECLAV Descriptor.

7) B05[O-B]: presence/absence of [O-B] at topological distance 05 (2D binary fingerprint) Dragon Descriptor.

8) GVWAI-50: Ghose-Viswanadhan-Wendoloski druglike index at $50 \%$ (molecular properties) Dragon Descriptor.

9) B08[C-O]: presence/absence of [C-O] at topological distance 08. (2D b inaryfingerprint) Dragon Descriptor.

10) HTm: H total index/weighted by atomic masses (GETAWAY descriptors).

These descriptors are chosen on the basis of their quality $(\mathrm{Q})$ and were used to generate the best MLR (Multilinear regression) model.

Finally, the leave-one-out (LOO) cross-validation procedure is applied to each and every MLR equation in order to estimate the prediction power of the proposed QSAR equations. The predictive ability of a QSAR equation is estimated with the LOO Pearson and Rank
(Kendall) correlation coefficients $\mathrm{R}_{\mathrm{cv}}^{2}$ and $\mathrm{R}_{\text {Kendall }}^{2}$. The equation with the highest predictive power is considered to be the one with the highest value for the product $R_{\mathrm{cv}}^{2}$ $\times \mathrm{R}_{\text {Kendall }}^{2}$. This QSAR model can further be used to predict the activity of novel, not yet tested compounds (Drugs).

In the present study for modeling $\log \mathrm{K}_{\mathrm{i}}$ of 78 compounds initially we have used 400 PRECLAV and 1457 DRAGON descriptors. The number of excluded near constant descriptors being 89 , while the number of significant descriptors is 174 . One by one outliers is removed from calibration set so that final 2D-QSAR model is obtained.

\section{Results and Discussion}

After computing the structural descriptors for the 78 flavones (Table 1) PRECLAV performs the descriptors solution and generation of best QSAR equation. Because it is important to have a reference for the evaluation of MLR model, we give here correlations prediction/property of the aforementioned most valuable predictors MATS2P, 0.444175: OXX, 0.2524; NGS, 0.1232; HBA, 0.1232; VLS, 0.112; BO5[O-Br], 0.1035; GVWAI-50, 0.0886 ; BO8[C-O], 0.0836; $\mathrm{HT}_{\mathrm{m}}, 0.0607$.

During the PRECLAV MLR analysis, we observed that the equation with highest value of the $R_{\mathrm{cv}}^{2} \times R_{\text {Kendall }}^{2}$ is the 7-parametric models and that this model also has the highest predictive power and is as follows.

$$
\begin{aligned}
& \log \mathrm{K}_{\mathrm{i}}=-2.5590-14.7642 \mathrm{MATS} 2 \mathrm{P}+0.8940 \mathrm{OXX} \\
&+0.5971 \mathrm{NGS}-1.0633 \mathrm{HBA}+1.0633 \mathrm{XNC} \\
&+0.0656 \mathrm{HTm}+4.3878 \mathrm{R} 2 \mathrm{U} . \\
& \mathrm{N}= 78, \mathrm{R}^{2}=0.7150, \mathrm{~F}=24.447, \mathrm{R}_{\text {kendal }}^{2}=0.6424, \\
& \mathrm{R}_{\mathrm{cv}}^{2}=0.6459, \mathrm{R}_{\mathrm{kcv}}=0.6063, \mathrm{Q}=0.5879 .
\end{aligned}
$$

A detailed regression analysis of this model using PRECLAV software indicated that there are seven compounds which are $(67,59,40,25,38,46$, and 64$)$ acting as outliers. These compounds are, therefore, removed for obtaining an appropriate model.

Also, note that in the above model the coefficient of MATS2P, HBA, and GVWAI-50 are negative indicating that $\log \mathrm{K}_{\mathrm{i}}$ increases with decrease in the magnitude of these predictors. Both Pearson and Kendall LOO coefficients are high showing that the equation can provide reliable predictions. Furthermore, despite the larger number of structural descriptors in the above equation there is no evidence of over fitting, as indicated by high values of $R_{c v}^{2}$ and $R_{\text {Kendal. }}^{2}$.

It is worth mentioning that one by one removal of compounds $67,59,40,25,38,36$, and 64 acting as outliers resulted into both changes in the number of descriptors as well as the regression quality. The statistical 
Table 1. List of 78 flavoniods and their observed $\log K_{i}$ values.<smiles>O=c1cc(-c2ccccc2)oc2ccccc12</smiles>

\begin{tabular}{|c|c|c|}
\hline Compd. No & Compound & Obs. $\log \mathrm{K}_{\mathrm{i}}$ \\
\hline 1 & 6-F-luoro-3'-methoxyflavone & 0.398 \\
\hline 2 & 6-Bromo-3'-mcthoxyflavone & -0.215 \\
\hline 3 & 6-Chloro-4'-methoxyflavonc & 0.097 \\
\hline 4 & 6-Bromo-4'-methoxyflavone & 0.322 \\
\hline 5 & 6-Chloro-2'-fluoroflavone & -0.380 \\
\hline 6 & 6-Bromo-2'-fluoroflavone & -0.424 \\
\hline 7 & 6,3'-Difluoroflavone & -0.036 \\
\hline 8 & 6-Chloro-3'-fluoroflavone & -0.9 .2 \\
\hline 9 & 6-Bromo-3'-fluoroflavone & -1.377 \\
\hline 10 & 4'-Fluoroflavonc & 0.556 \\
\hline 11 & 6.4'-Difluoroflavone & 0.398 \\
\hline 12 & 6-Chloro-4'-fluoroflavone & -0.742 \\
\hline 13 & 3'-Chloroflavone & -0.212 \\
\hline 14 & 6,3'-Dichloroflavone & -1.638 \\
\hline 15 & 3'-Bromoflavone & -0.384 \\
\hline 16 & 6-Fluoro-3'-bromoflavone & -0.627 \\
\hline 17 & 6-Chloro-3'-bromoflavone & -1.638 \\
\hline 18 & 6,3'-Dibromollavone & -1.721 \\
\hline 19 & 6-Bromo-4'-nitroflavone & -0.699 \\
\hline 20 & 6-Bromoflavone & -1.155 \\
\hline 21 & 6-Chloroflavone & -0.785 \\
\hline 22 & 6-Nitroflavone & -0.561 \\
\hline 23 & 6-Methoxyllavone & -0.066 \\
\hline 24 & 6-Fluoroflavone & 0.653 \\
\hline 25 & 6-Bromo-3'-nitroflavone & -3.000 \\
\hline 26 & 6-Methyl-3'-nitroflavone & -2.252 \\
\hline 27 & 6-Chloro-3'-nitroflavone & -2.097 \\
\hline 28 & 6-3'-Dinitroflavone & -1.585 \\
\hline 29 & 6-Fluoro-3'-nitroflavone & -0.745 \\
\hline 30 & 3'-Nitroflavonc & -0.545 \\
\hline 31 & 6-Methyl-3'-bromoflavone & -1.886 \\
\hline 32 & 6-Nitro-3'-bromoflavone & -1.602 \\
\hline 33 & 6-Hydroxy-3'-bromoflavone & 0.000 \\
\hline 34 & 6-Methoxy-3'-bromoflavone & 0.000 \\
\hline 35 & 6-3'-Dimethylflavone & -0.682 \\
\hline
\end{tabular}

\begin{tabular}{|c|c|c|}
\hline 36 & 3'-Methylflavone & 1.000 \\
\hline 37 & $\begin{array}{l}\text { 5,2'-Dihydroxy- } 6,7,8,6 \text { '-tetramethoxy } \\
\text { flavone }\end{array}$ & -0.444 \\
\hline 38 & 5,7,2'-Trihydroxy-6,8-dimethoxyflavone & -2.215 \\
\hline 39 & 2'-Hydroxy-a-napthoflavone & -1.569 \\
\hline 40 & 6.2'-Dihydroxyflavone & -1.469 \\
\hline 41 & 5,7,2'-Trihydroxy-b.-methoxyflavone & -1.420 \\
\hline 42 & 5,7,2'-Trihydroxyflavone & -1.125 \\
\hline 43 & 2'-Hydroxyflavone & -0.678 \\
\hline 44 & 5.7-Dihydroxy-6.8-dimethoxyflavone & -0.699 \\
\hline 45 & 7,2'-Dihydroxyflavone & -0.252 \\
\hline 46 & 5,7-Dihydroxy-6-methoxyflavone & -0.051 \\
\hline 47 & 5.7-Dihydroxy-8-methoxyflavone & 0.182 \\
\hline 48 & 6-F Hydroxyflavone & 0.422 \\
\hline 49 & 7-Hydroxyflavone & 0.623 \\
\hline 50 & 5,6,7-Trihydroxyflavone & 0.747 \\
\hline 51 & 6-Hydroxy-2'-mcthoxytlavone & 0.976 \\
\hline 52 & 2'-Methoxyflavone & 1.508 \\
\hline 53 & 2'-Amino-6-methoxyflavone & 0.544 \\
\hline 54 & Flavone & 0.000 \\
\hline 55 & 5,7-Dihydroxyflavone & 0.477 \\
\hline 56 & 5,3',4'-Trihydroxy-6,7-dimethoxyflavone & 2.301 \\
\hline 57 & 5,4'-Dihydroxy-6,7-dimcthoxyflavone & 1.362 \\
\hline 58 & 5,7,4'-Trihydroxy-6-mcthoxyflavone & 0.000 \\
\hline 59 & 5,7-Dihydroxy-2'-chloroflavone & 0.903 \\
\hline 60 & 5,7-Dihydroxy-2'-fluoroflavone & 0.903 \\
\hline 61 & 5,7-Dihydroxy-6,8-dibromoflavone & -0.155 \\
\hline 62 & 5,7,4'-Trihydroxyflavone & 0.602 \\
\hline 63 & 3,5,7,4'-Tetrahydroxytlavone & 1.969 \\
\hline 64 & 5-Hydroxy-7-methoxyllavone & 1.699 \\
\hline 65 & 5,7-Dihydroxy-6,8-diiodollavone & 0.000 \\
\hline 66 & 6-Fluoro,3'-hydroxyflavone & 0.400 \\
\hline 67 & 6-Chloro,3'-hydroxyflavone & -0.070 \\
\hline 68 & 6-Bromo,3'-hydroxyflavone & -0.220 \\
\hline 69 & 6-Bromo-2'-nitrotlavone & -0.680 \\
\hline 70 & 6-Nitro-4'-bromollavone & -1.600 \\
\hline 71 & 3'-Methoxyflavone & 0.380 \\
\hline 72 & 6-Chloro-3'-methoxyflavone & -0.072 \\
\hline 73 & 3'-Fluoroflavone & 0.550 \\
\hline 74 & 6-Bromo-4'-fluoroflavone & -0.939 \\
\hline 75 & 6-Fluoro-3'-chlorollavone & -0.701 \\
\hline 76 & 6-Bromo-3'-chlorollavone & -1.770 \\
\hline 77 & 6-Methylflavone & -0.903 \\
\hline 78 & 6-Bromo-3'-methylflavone & -0.812 \\
\hline
\end{tabular}


detail of this model is given below:

$$
\begin{aligned}
\log \mathrm{K}_{\mathrm{i}}= & -2.9314-16.6179 \mathrm{MATS} 2 \mathrm{P}+0.8709 \mathrm{OXX} \\
& +0.4905 \mathrm{NGS}-1.8923 \mathrm{HBA}+0.3671 \mathrm{VLS} \\
& -0.34610 .5135 \mathrm{BO} 5[\mathrm{O}-\mathrm{Br}] \\
& -0.3461 \mathrm{GVWAI}-50+0.7031 \mathrm{BO} 8[\mathrm{C}-\mathrm{O}] \\
& +0.0489 \mathrm{HT}_{\mathrm{m}} \\
\mathrm{N}= & 71, \mathrm{R}^{2}=0.8098, \mathrm{~F}=29.333, \mathrm{R}_{\text {kendal }}^{2}=0.7095, \\
& \mathrm{R}_{\mathrm{cv}}^{2}=0.7494, \mathrm{R}_{\mathrm{kcv}}=0.6732, \mathrm{Q}=0.6544
\end{aligned}
$$

We observed that the quality and predictive power of the earlier model is considerably improved after deletion of outliers. Furthermore, the physical significance of the involved parameters is the same as before.

We have also used PRECLAV descriptors for obtaining the best 2D-QSAR model using NCSS software. Variable selection for multiple regression analysis has demonstrated the occurrence of best regression model with nine correlating parameters using variable selection analysis (Table 2). These parameters are the same as those were used in the aforementioned PRECLAV QSAR modeling. However, unlike PRECLAV, the NCSS programs clearly demonstrate successive arrival of 9-para- metric model. (Table 2). Among the regression results the best one-, two-, three-, four-, five-, six-, seven-, eight- and nineparametric models were selected and are given in Table 3.

In these models, the correlation coefficient, $\mathrm{R}^{2}$, is a measure of the fit of the model. F, the Fisher test value, reflects the ratio of the variance explained by the model and the variance due to the error in the model. Higher values of F-test indicate the significance of the model.

A perusal of Table 3 shows that using NCSS software

\begin{tabular}{|c|c|c|c|c|c|c|c|c|c|}
\hline Model No & $\mathbf{R}^{2}$ & $\mathbf{R}_{\mathrm{A}}^{2}$ & $\mathbf{C V}$ & $\mathbf{F}$ & $\mathbf{Q}$ & PRESS/SSY & $\mathbf{R}_{\mathrm{CV}}^{2}$ & S $_{\text {PRESS }}$ & PSE \\
\hline 1 & 0.4175 & 0.4091 & -2.2701 & 49.464 & -0.2846 & 1.3950 & -0.3950 & 0.7260 & 0.7157 \\
\hline 2 & 0.5359 & 0.5222 & -2.0413 & 39.255 & -0.3586 & 0.8661 & 0.1339 & 0.6528 & 0.6389 \\
\hline 3 & 0.5940 & 0.5758 & -1.9234 & 32.675 & -0.4007 & 0.6835 & 0.3165 & 0.6151 & 0.5975 \\
\hline 4 & 0.6605 & 0.6399 & -1.7722 & 32.095 & -0.4586 & 0.5141 & 0.4859 & 0.5668 & 0.5464 \\
\hline 5 & 0.7140 & 0.6920 & -1.6391 & 32.448 & -0.5155 & 0.4006 & 0.5994 & 0.5242 & 0.5015 \\
\hline 6 & 0.7462 & 0.7225 & -1.5558 & 31.368 & -0.5552 & 0.3401 & 0.6599 & 0.4976 & 0.4724 \\
\hline 7 & 0.7714 & 0.7460 & -1.4483 & 30.372 & -0.6064 & 0.2963 & 0.7037 & 0.4760 & 0.4484 \\
\hline 8 & 0.7929 & 0.7662 & -1.4280 & 29.672 & -0.6236 & 0.2612 & 0.7388 & 0.4567 & 0.4268 \\
\hline 9 & 0.8098 & 0.7818 & -1.3797 & 28.860 & -0.6522 & 0.2349 & 0.7651 & 0.4412 & 0.4090 \\
\hline
\end{tabular}
statistically allowed models start pouring with two- and higher-parametric modeling. The regression parameters and quality of these models are given below:

Table 2. Variable selection for multiple regression using NCSS.

\begin{tabular}{cccl}
\hline Model No & \multicolumn{1}{c}{$\mathbf{R}^{2}$} & $\mathbf{R}^{2}$-Change & \multicolumn{1}{c}{ Names } \\
\hline 1 & 0.4175 & 0.4175 & MATS2p \\
2 & 0.5359 & 0.1183 & MATS2p, OXX \\
3 & 0.5940 & 0.0581 & MATS2p, OXX, HTm \\
4 & 0.6605 & 0.0665 & MATS2p, OXX, HBA, HTm \\
5 & 0.7140 & 0.0535 & MATS2p, OXX, NGS, HBA, HTm \\
6 & 0.7462 & 0.0323 & MATS2p, OXX, NGS, HBA, B08[C-O], HTm \\
7 & 0.7714 & 0.0252 & MATS2p, OXX, NGS, HBA, B05[O-Br], B08[C-O], HTm \\
8 & 0.7929 & 0.0215 & MATS2p, OXX, NGS, HBA, VLS, B05[O-Br], B08[C-O], HTm \\
9 & 0.8098 & 0.0169 & MATS2p, OXX, NGS, HBA, VLS, B05[O-Br], GVWAI-50, B08[C-O], HTm \\
\hline
\end{tabular}

Table 3. Quality of regression and predictive potential for one to nine variable models. 


$$
\begin{aligned}
& \text { Two-variable model } \\
& \begin{array}{r}
\log \mathrm{K}_{\mathrm{i}}= \\
\quad 0.6987-7.0909( \pm 1.1003) \mathrm{MATS} 2 \mathrm{p} \\
+0.6765( \pm 0.1625) \mathrm{OXX}
\end{array} \\
& \mathrm{N}=71, \mathrm{R}^{2}=0.5339, \mathrm{R}_{\mathrm{A}}^{2}=0.5222, \mathrm{CV}=-2.0413 \\
& \mathrm{~F}=39.255
\end{aligned}
$$

The positive coefficient of the parameter OXX indicates that presence of Oxygen Maximum charge for $\mathrm{O}$ atom (at parabolic region) is favourable for the exhibition of the activity.

\section{Three-variable model}

$$
\begin{gathered}
\log \mathrm{K}_{\mathrm{i}}=-1.2772-9.4417( \pm 1.2848) \mathrm{MATS} 2 \mathrm{p} \\
+0.7375( \pm 0.1544) \mathrm{OXX} \\
+0.0296( \pm 0.0095) \mathrm{HTm} \\
\mathrm{N}=71, \mathrm{R}^{2}=0.5940, \quad \mathrm{R}_{\mathrm{A}}^{2}=0.5758, \mathrm{CV}=-1.9234 \\
\mathrm{~F}=32.675
\end{gathered}
$$

Here the coefficients of both the parameters OXX and HTm are positive meaning thereby that presence of Oxygen Maximum charge for $\mathrm{O}$ atom (at parabolic region) as well as $\mathrm{H}$ total index/weighted by atomic masses are favourable for the exhibition of the activity.

\section{Four-variable model}

$$
\begin{gathered}
\log \mathrm{K}_{\mathrm{i}}=-2.1460-13.1294( \pm 1.5666) \mathrm{MATS} 2 \mathrm{p} \\
+0.9464( \pm 0.1536) \mathrm{OXX} \\
+0.0471( \pm 0.0101) \mathrm{HTm} \\
-1.1215( \pm 0.3120) \mathrm{HBA} \\
\mathrm{N}=71, \mathrm{R}^{2}=0.6605, \mathrm{R}_{\mathrm{A}}^{2}=0.6399, \mathrm{CV}=-1.7722 \\
\mathrm{~F}=32.095
\end{gathered}
$$

Here also the parameters OXX and HTm have positive coefficients meaning thereby that presence of Oxygen Maximum charge for $\mathrm{O}$ atom (at parabolic region) as well as $\mathrm{H}$ total index/weighted by atomic masses are favourable for the exhibition of the activity

\section{Five-variable model}

$$
\begin{aligned}
& \log \mathrm{K}_{\mathrm{i}}=-2.0375-13.1086( \pm 1.4489) \mathrm{MATS} 2 \mathrm{p} \\
&+0.9128( \pm 0.1424) \mathrm{OXX} \\
&+0.0499( \pm 0.0093) \mathrm{HTm} \\
&-1.2511( \pm 0.291 \mathrm{HTm} 0) \mathrm{HBA} \\
&+0.6149( \pm 0.1763) \mathrm{NGS} \\
& \mathrm{N}=71, \mathrm{R}^{2}=0.7140, \quad \mathrm{R}_{\mathrm{A}}^{2}=0.6920, \mathrm{CV}=-1.6391 \\
& \mathrm{~F}=32.448
\end{aligned}
$$

In this model, in addition to the two parameters OXX and HTm the third parameter NGS has positive coefficient. This means that in addition to presence of Oxygen Maximum charge for $\mathrm{O}$ atom (at parabolic region) as well as $\mathrm{H}$ total index/weighted by atomic masses, the area of negative charged surface/molecular surface area ratio (at parabolic region) is also favourable for the exhibition of the activity.

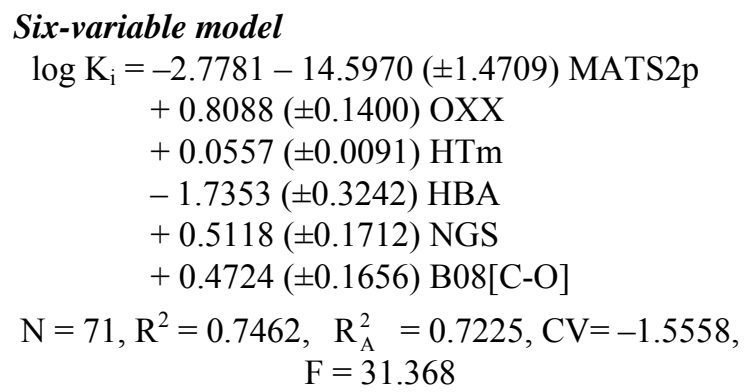

We observe that in this model, in addition to the aforementioned three parameters a fourth parameter viz. B08 [C-O] has positive coefficient clearly meaning thereby that presence of Oxygen Maximum charge for $\mathrm{O}$ atom (at parabolic region) as well as $\mathrm{H}$ total index/weighted by atomic masses, the area of negative charged surface/ molecular surface area ratio (at parabolic region), the presence/absence of $\mathrm{C}-\mathrm{O}$ at topological distance 08 . (2D binary fingerprint) also favours the exhibition of the activity.

\section{Seven-variable model}

$$
\begin{aligned}
& \log \mathrm{K}_{\mathrm{i}}=-3.0056-16.0272( \pm 1.5082) \mathrm{MATS} 2 \mathrm{p} \\
&+0.8461( \pm 0.1347) \mathrm{OXX} \\
&+0.0509( \pm 0.0089) \mathrm{HTm} \\
&-1.8204( \pm 0.3118) \mathrm{HBA} \\
&+0.5333( \pm 0.1640) \mathrm{NGS} \\
&+0.5286( \pm 0.1598) \mathrm{B} 08[\mathrm{C}-\mathrm{O}] \\
&+0.4638( \pm 0.1761) \mathrm{BO}[\mathrm{O}-\mathrm{Br}] \\
& \mathrm{N}=71, \mathrm{R}^{2}=0.7714, \quad \mathrm{R}_{\mathrm{A}}^{2}=0.7460, \mathrm{CV}=-1.4883 \\
& \mathrm{~F}=30.372
\end{aligned}
$$

In this model, in addition to the positive coefficients of the aforementioned four parameters, the fifth parameter namely $\mathrm{BO} 5[\mathrm{O}-\mathrm{Br}]$ also has positive coefficient. It means that in addition to presence of Oxygen Maximum charge for $\mathrm{O}$ atom (at parabolic region) as well as $\mathrm{H}$ total index/weighted by atomic masses, the area of negative charged surface/molecular surface area ratio (at parabolic region), the presence/absence of $\mathrm{C}-\mathrm{O}$ at topological distance 08 . (2D binary fingerprint), the presence/absence of $\mathrm{O}-\mathrm{B}$ at topological distance 05 (2D binary fingerprint) also favours the exhibition of the activity.

\section{Eight-variable model}

$$
\begin{aligned}
& \log \mathrm{K}_{\mathrm{i}}=-2.7789-15.4338( \pm 1.4659) \mathrm{MATS} 2 \mathrm{p} \\
&+0.8315( \pm 0.1294) \mathrm{OXX} \\
&+0.0505( \pm 0.0085) \mathrm{HTm} \\
&-1.7761( \pm 0.2996) \mathrm{HBA} \\
&+0.5435( \pm 0.1574) \mathrm{NGS} \\
&+0.4955( \pm 0.1539) \mathrm{B} 08[\mathrm{C}-\mathrm{O}] \\
&+0.4533( \pm 0.1690) \mathrm{BO} 5[\mathrm{O}-\mathrm{Br}] \\
&+0.4045( \pm 0.1595) \mathrm{VLS} \\
& \mathrm{N}=71, \mathrm{R}^{2}=0.7929, \quad \mathrm{R}_{\mathrm{A}}^{2}=0.7662, \mathrm{CV}=-1.4280 \\
& \mathrm{~F}=29.672
\end{aligned}
$$


Here, we observe that in addition to the positive coefficients of the above mentioned five parameters, the six parameter namely VLS also has positive coefficient. This clearly means that in addition to the presence of Oxygen Maximum charge for $\mathrm{O}$ atom (at parabolic region) as well as $\mathrm{H}$ total index/weighted by atomic masses, the area of negative charged surface/molecular surface area ratio (at parabolic region), the presence/absence of [C-O] at topological distance 08 . (2D binary fingerprint), the presence/ absence of [O-B] at topological distance 05 (2D binary fingerprint), volume of circumscribed sphere (at parabolic region) also favours the exhibition of the activity.

\section{Nine-variable model}

$$
\begin{aligned}
& \log \mathrm{K}_{\mathrm{i}}=-2.9314-16.6178( \pm 1.5048) \mathrm{MATS} 2 \mathrm{p} \\
&+0.8709( \pm 0.1261) \text { OXX } \\
&+0.0489( \pm 0.0083) \mathrm{HTm} \\
&-1.8923( \pm 0.2938) \mathrm{HBA} \\
&+0.4905( \pm 0.1538) \mathrm{NGS} \\
&+0.7031( \pm 0.1734) \mathrm{B} 08[\mathrm{C}-\mathrm{O}] \\
&+0.5135( \pm 0.1653) \mathrm{BO}[\mathrm{O}-\mathrm{Br}] \\
&+0.3672( \pm 0.1549) \mathrm{VLS} \\
&-0.3461( \pm 0.1486) \mathrm{GVWAI}-50 \\
& \mathrm{~N}=71, \mathrm{R}^{2}=0.8098, \quad \mathrm{R}_{\mathrm{A}}^{2}=0.7818, \mathrm{CV}=-1.3797 \\
& \mathrm{~F}=28.860
\end{aligned}
$$

We observe that in this 9-parametric model the aforementioned six correlating parameters have positive coefficients .This means that their physical significance in this model is the same as that of the 8-parametric model discussed above.

The aforementioned 9-variable model is, therefore, the most appropriate model and is subjected to Ridge regression [25] for investigating the existence or otherwise of any co-linearity defect. The Ridge parameters, namely VIF (variance inflation factor), T (Tolerance), CN (Condition number), have been calculated and presented in Table 4. We observed that VIF (variance inflation factor)values are much smaller than the allowed range of 10 . Also, that condition number for for the correlating parameters all are much lower than 100 and the tolerance are $<1$. These observations therefore, suggest that no colinearity defect is present in the proposed model.

Relative performance of PRECLAV and NCSS software

In order to further investigate the relative performance of both PRECLAV as well as NCSS software we have calculated (estimated) $\log \mathrm{K}_{\mathrm{i}}$ values for the 9-parametric models using both softwares and compared them with the experimental values of $\log K_{i}$ (Table 5). This is demonstrated in Figures $\mathbf{1}$ and $\mathbf{2}$ indicating that quality of the model obtain from both PRECLAV and NCSS software is more or less same. $\log \mathrm{K}_{\mathrm{i}}$ values are much closer to the experimental values in case of PRECLAV software.

\begin{tabular}{|c|c|}
\hline PRECLAV & NCSS \\
\hline 1) Overall the best model is proposed & $\begin{array}{l}\text { 1) Recommends obtaining of the best model in succession which need to } \\
\text { be confirmed by their means }\end{array}$ \\
\hline $\begin{array}{l}\text { 2) Predicts and removes the outliers one by one during the regression so } \\
\text { that the final model does not have any outlier }\end{array}$ & 2) This is not possible \\
\hline 3) Performance cross-validation & 3) Not possible \\
\hline 4) Selects most significant descriptors by quality & 4) Selection of descriptors is not based on quality \\
\hline 5) Most valuable descriptors set is generated & 5) Not possible \\
\hline 6) Correlation of predictor/activity is possible & 6) Not possible \\
\hline 7) Yields inter correlation of predictors & 7) Not possible \\
\hline 8) Makes estimated and observed values in calibration set & 8) Yes it is also possible in NCSS \\
\hline 9) Analysis virtual fragments is possible & 9) Not possible \\
\hline 10) Standard deviation of coefficients are not measured & $\begin{array}{l}\text { 10) We can estimate standard error of the coefficient of the correlating } \\
\text { parameters }\end{array}$ \\
\hline 11) Ridge statistics is not possible & 11) We can make ridge analysis and then investigate co- linearity defect \\
\hline 12) Estimate qulity $Q$ of the model & 12) Not possible \\
\hline
\end{tabular}
From the study made herein we cannot definitely say as to which software is superior. Both have their own merits and demerits. However, the number of good points are more in PRECLAV software as compared to NCSS software. From the results obtained we conclude that there are some good or bad points in both the software and that overall PRECLAV software yields better statistics compared to NCSS software. The comparison of the performance of this software is demonstrated as below:

\section{Comparison of results obtained using PRECLAV and NCSS software.}


It is worth mentioning that one of the important features of PRECLAV software is the analysis of virtual fragments. The software has indicated that for the set of 78 molecules analyzed here 30 virtual fragments are present out of which 9 fragments are significant. These most significant virtual fragments by correlation of "The Mass percent" and "Property values" are given in Table 6. This Table 6 demonstrates that large mass percent of $\mathrm{CO}$, $\mathrm{C}_{9} \mathrm{H}_{4} \mathrm{O}_{4}, \mathrm{C}_{6} \mathrm{H}_{5} \mathrm{O}_{7}, \mathrm{C}_{6} \mathrm{H}_{4} \mathrm{O}$, and $\mathrm{C}_{8} \mathrm{H}_{5} \mathrm{O}_{4}$ increases $\log \mathrm{K}_{\mathrm{i}}$ values while the large mass percent at $\mathrm{C}_{8} \mathrm{H}_{4} \mathrm{O}, \mathrm{NO}_{2}, \mathrm{Br}$ and $\mathrm{C}_{6} \mathrm{H}_{4}$ decreases the $\log \mathrm{K}_{\mathrm{i}}$ values. These observations, therefore, be taken care of while synthesizing new flavones with better $\log \mathrm{K}_{\mathrm{i}}$ values.

In order to confirm our findings we have compared the estimated values of the activities $\left(\log \mathrm{K}_{\mathrm{i}}\right)$ with the experimental ones $\left(\log \mathrm{K}_{\mathrm{i}}\right.$ ) (Table 5). This has further been demonstrated in Figures 1 and 2. Also, we have obtained Ridge traces as shown in Figures $\mathbf{3}$ and 4. From Figures $\mathbf{1}$ and $\mathbf{2}$ as well as Table 5, we observed that the estimated activities $\left(\log \mathrm{K}_{\mathrm{i}}\right)$ are very close to the experimen- tal activities $\left(\log \mathrm{K}_{\mathrm{i}}\right)$. Similarly, Figures $\mathbf{3}$ and $\mathbf{4}$ indicates absence of any co-linearity defect.

Table 4. Ridge parameters for the most significant model.

\begin{tabular}{lcccc}
\hline \multicolumn{1}{c}{ Variable } & VIF & $\mathrm{T}$ & $\lambda_{\mathrm{i}}$ & $\mathrm{CN}$ \\
\hline MATS2p & 4.4014 & 0.2272 & 3.367143 & 1.00 \\
OXX & 1.4179 & 0.7053 & 1.446224 & 2.33 \\
NGS & 1.1562 & 0.8649 & 0.957829 & 3.52 \\
HBA & 2.9861 & 0.3349 & 0.919456 & 3.66 \\
VLS & 1.0819 & 0.9243 & 0.771579 & 4.36 \\
B05[O-Br] & 1.9536 & 0.5119 & 0.643925 & 5.23 \\
GVWAI-50 & 1.8986 & 0.5267 & 0.460259 & 7.32 \\
B08[CO] & 2.5441 & 0.3931 & 0.316425 & 10.64 \\
HTm & 2.3977 & 0.4171 & 0.117160 & 28.74 \\
\hline
\end{tabular}

Table 5. Comparison of $\log \mathrm{K}_{\mathrm{i}}$ values estimated using PRECLAV and NCSS Software.

\begin{tabular}{|c|c|c|c|c|c|}
\hline \multicolumn{3}{|c|}{ Using PRECLAV } & \multicolumn{3}{|c|}{ Using NCSS } \\
\hline Compd. No & Obs. $\log \mathrm{Ki}$ & Est. $\log \mathrm{K}_{\mathrm{i}}$ & Residual & Est. $\log \mathrm{Ki}$ & Residual \\
\hline 1 & 0.398 & 0.501 & -0.103 & 0.501 & -0.103 \\
\hline 2 & -0.215 & -0.373 & 0.158 & -0.373 & 0.158 \\
\hline 3 & 0.097 & 0.228 & -0.131 & 0.228 & -0.131 \\
\hline 4 & 0.322 & 0.084 & 0.238 & 0.084 & 0.238 \\
\hline 5 & -0.380 & -0.898 & 0.518 & -0.898 & 0.518 \\
\hline 6 & -0.424 & 0.067 & -0.491 & 0.067 & -0.491 \\
\hline 7 & -0.036 & 0.067 & -0.103 & 0.067 & -0.103 \\
\hline 8 & -0.932 & -0.855 & -0.077 & -0.855 & -0.077 \\
\hline 9 & -1.377 & -1.013 & -0.364 & -1.013 & -0.364 \\
\hline 10 & 0.556 & -0.118 & 0.674 & -0.118 & 0.674 \\
\hline 11 & 0.398 & -0.042 & 0.44 & -0.042 & 0.440 \\
\hline 12 & -0.742 & -0.743 & 0.001 & -0.743 & 0.001 \\
\hline 13 & -0.212 & -0.76 & 0.548 & -0.760 & 0.548 \\
\hline 14 & -1.638 & -1.446 & -0.192 & -1.446 & -0.192 \\
\hline 15 & -0.384 & -0.641 & 0.257 & -0.641 & 0.257 \\
\hline 16 & -0.627 & -0.267 & -0.36 & -0.267 & -0.360 \\
\hline 17 & -1.638 & -1.302 & -0.336 & -1.302 & -0.336 \\
\hline 18 & -1.721 & -1.208 & -0.513 & -1.208 & -0.513 \\
\hline 19 & -0.699 & -0.828 & 0.129 & -0.828 & 0.129 \\
\hline
\end{tabular}



(Property-Evaluation by Class Variables)

\begin{tabular}{|c|c|c|c|c|c|}
\hline 20 & -1.155 & -1.285 & 0.13 & -1.285 & 0.130 \\
\hline 21 & -0.785 & -1.056 & 0.271 & -1.056 & 0.271 \\
\hline 22 & -0.561 & -0.992 & 0.431 & -0.992 & 0.431 \\
\hline 23 & -0.066 & 0.535 & -0.601 & 0.535 & -0.601 \\
\hline 24 & 0.653 & 0.256 & 0.397 & 0.256 & 0.397 \\
\hline 25 & Outlier & & & & \\
\hline 26 & -2.252 & -1.941 & -0.311 & -1.941 & -0.311 \\
\hline 27 & -2.097 & -1.751 & -0.346 & -1.751 & -0.346 \\
\hline 28 & -1.585 & -1.868 & 0.283 & -1.868 & 0.283 \\
\hline 29 & -0.745 & -0.463 & -0.282 & -0.463 & -0.282 \\
\hline 30 & -0.545 & -1.07 & 0.525 & -1.070 & 0.525 \\
\hline 31 & -1.886 & -1.285 & -0.601 & -1.285 & -0.601 \\
\hline 32 & -1.602 & -0.92 & -0.682 & -0.920 & -0.682 \\
\hline 33 & 0.000 & -0.015 & 0.015 & -0.015 & 0.015 \\
\hline 34 & 0.000 & -0.414 & 0.414 & -0.414 & 0.414 \\
\hline 35 & -0.682 & -0.631 & -0.051 & -0.631 & -0.051 \\
\hline 36 & Outlier & & & & \\
\hline 37 & -0.444 & -0.485 & 0.485 & -0.485 & 0.041 \\
\hline 38 & Outlier & & & & \\
\hline 39 & -1.569 & -1.114 & -0.455 & -1.114 & -0.455 \\
\hline 40 & Outlier & & & & \\
\hline 41 & -1.420 & -0.757 & -0.663 & -0.757 & -0.663 \\
\hline 42 & -1.125 & -0.293 & -0.832 & -0.293 & -0.832 \\
\hline 43 & -0.678 & 0.178 & -0.856 & 0.178 & -0.856 \\
\hline 44 & -0.699 & -0.976 & 0.277 & -0.976 & 0.277 \\
\hline 45 & -0.252 & 0.148 & -0.4 & 0.148 & -0.400 \\
\hline 46 & -0.051 & 0.131 & -0.182 & 0.131 & -0.182 \\
\hline 47 & 0.182 & 0.004 & 0.178 & 0.004 & 0.178 \\
\hline 48 & 0.422 & 0.948 & -0.526 & 0.948 & -0.526 \\
\hline 49 & 0.623 & 0.736 & -0.113 & 0.736 & -0.113 \\
\hline 50 & 0.747 & 0.838 & -0.091 & 0.838 & -0.091 \\
\hline 51 & 0.976 & 0.986 & -0.01 & 0.986 & -0.010 \\
\hline 52 & 1.508 & 0.93 & 0.578 & 0.930 & 0.578 \\
\hline 53 & 0.544 & 0.228 & 0.316 & 0.228 & 0.316 \\
\hline 54 & 0.000 & -0.096 & 0.096 & -0.096 & 0.096 \\
\hline 55 & 0.477 & 0.805 & -0.328 & 0.805 & -0.328 \\
\hline
\end{tabular}



(Property-Evaluation by Class Variables)

\begin{tabular}{|c|c|c|c|c|c|}
\hline 56 & 2.301 & 1.944 & 0.357 & 1.944 & 0.357 \\
\hline 57 & 1.362 & 2.045 & -0.683 & 2.045 & -0.683 \\
\hline 58 & 0.000 & -0.638 & 0.638 & -0.638 & 0.638 \\
\hline 59 & Outlier & & & & \\
\hline 60 & 0.903 & 0.401 & 0.502 & 0.401 & 0.502 \\
\hline 61 & -0.155 & -0.79 & 0.635 & -0.790 & 0.635 \\
\hline 62 & 0.602 & 0.062 & 0.54 & 0.062 & 0.540 \\
\hline 63 & 1.969 & 1.588 & 0.381 & 1.587 & 0.382 \\
\hline 64 & Outlier & & & & \\
\hline 65 & 0.000 & -0.039 & 0.039 & -0.039 & 0.039 \\
\hline 66 & 0.400 & 0.162 & 0.238 & 0.162 & 0.238 \\
\hline 67 & Outlier & & & & \\
\hline 68 & -0.220 & -0.865 & 0.645 & -0.865 & 0.645 \\
\hline 69 & -0.680 & -1.133 & 0.453 & -1.133 & 0.453 \\
\hline 70 & -1.600 & -1.395 & -0.205 & -1.395 & -0.205 \\
\hline 71 & 0.380 & 0.688 & -0.308 & 0.688 & -0.308 \\
\hline 72 & -0.072 & -0.173 & 0.101 & -0.173 & 0.101 \\
\hline 73 & 0.550 & 0.064 & 0.486 & 0.064 & 0.486 \\
\hline 74 & -0.939 & -1.003 & 0.064 & -1.003 & 0.064 \\
\hline 75 & -0.701 & -0.313 & -0.388 & -0.313 & -0.388 \\
\hline 76 & -1.770 & -1.131 & -0.639 & -1.131 & -0.639 \\
\hline 77 & -0.903 & -0.776 & -0.127 & -0.776 & -0.127 \\
\hline 78 & -0.812 & -1.17 & 0.358 & -1.170 & 0.358 \\
\hline
\end{tabular}

Table 6. List of virtual fragments.

\begin{tabular}{ccccc}
\hline S. No & Fragment & $\begin{array}{c}\text { Specimen } \\
\text { Molecule }\end{array}$ & Correlation & F \\
\hline 1 & $\mathrm{C}_{8} \mathrm{H}_{4} \mathrm{O}$ & 1 & -0.4294 & 174.1 \\
2 & $\mathrm{NO}_{2}$ & 19 & -0.4006 & 147.1 \\
3 & $\mathrm{Br}$ & 2 & -0.3603 & 114.9 \\
4 & $\mathrm{CO}$ & 1 & 0.3422 & 102.1 \\
5 & $\mathrm{C}_{9} \mathrm{H}_{4} \mathrm{O}_{4}$ & 56 & 0.3405 & 100.9 \\
6 & $\mathrm{C}_{6} \mathrm{H}_{4}$ & 5 & -0.3177 & 86.4 \\
7 & $\mathrm{C}_{6} \mathrm{H}_{5} \mathrm{O}_{2}$ & 56 & 0.2928 & 72.2 \\
8 & $\mathrm{C}_{6} \mathrm{H}_{4} \mathrm{O}$ & 1 & 0.2592 & 55.5 \\
9 & $\mathrm{C}_{8} \mathrm{H}_{5} \mathrm{O}_{4}$ & 63 & 0.2559 & 54.0 \\
\hline
\end{tabular}

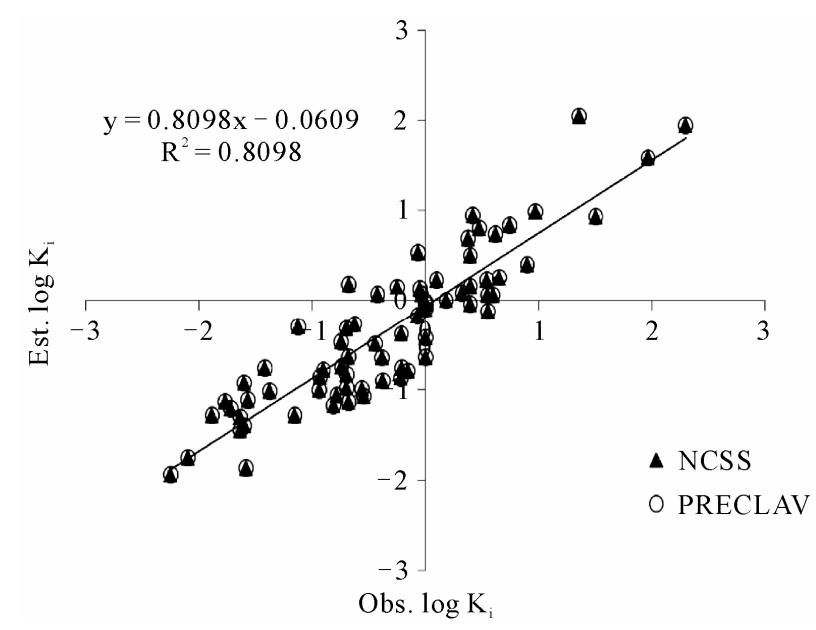

Figure 1. Correlation between observed and estimated $\log K_{i}$ using 9-parametric model both from PRECLAV and NCSS softwares. 


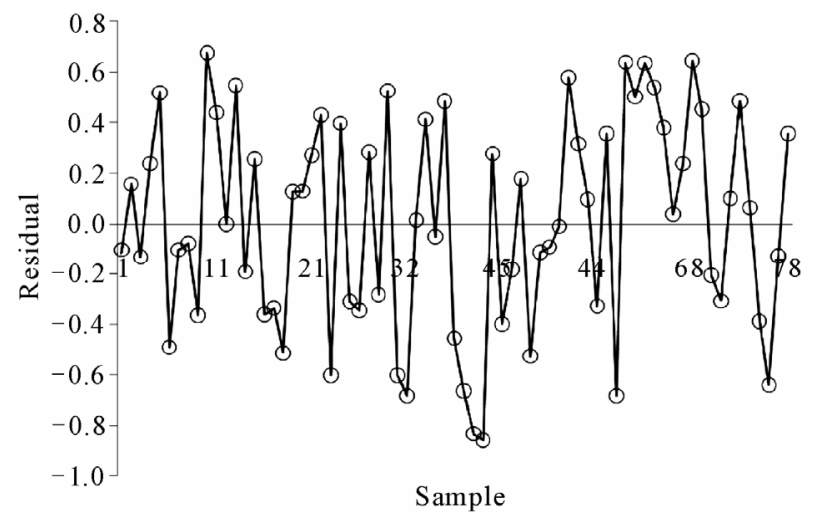

Figure 2. Residual plot for $\log K_{\mathbf{i}}$ using 9-parametric model both from PRECLAV and NCSS softwares.

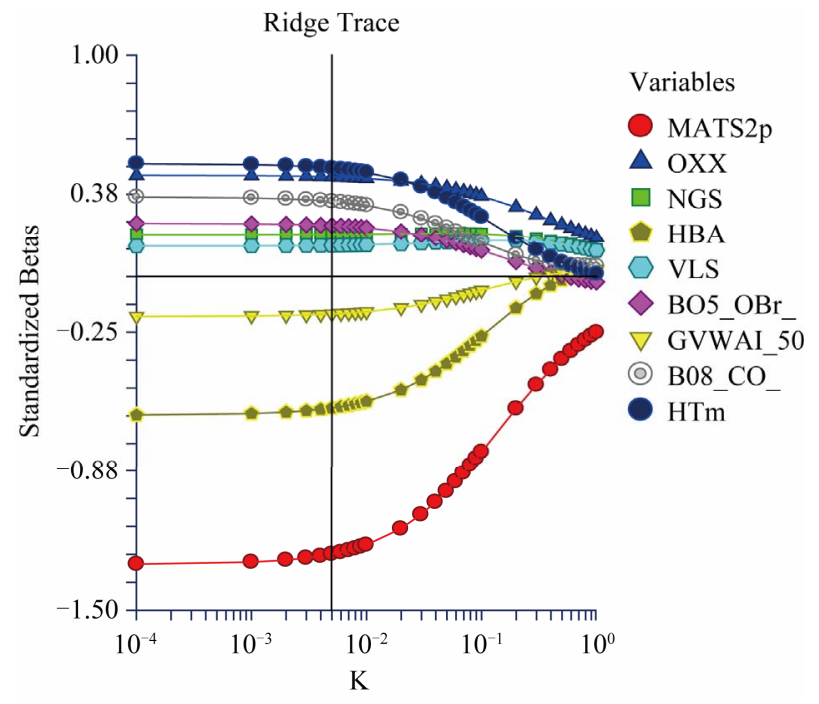

Figure 3. Ridge plot.

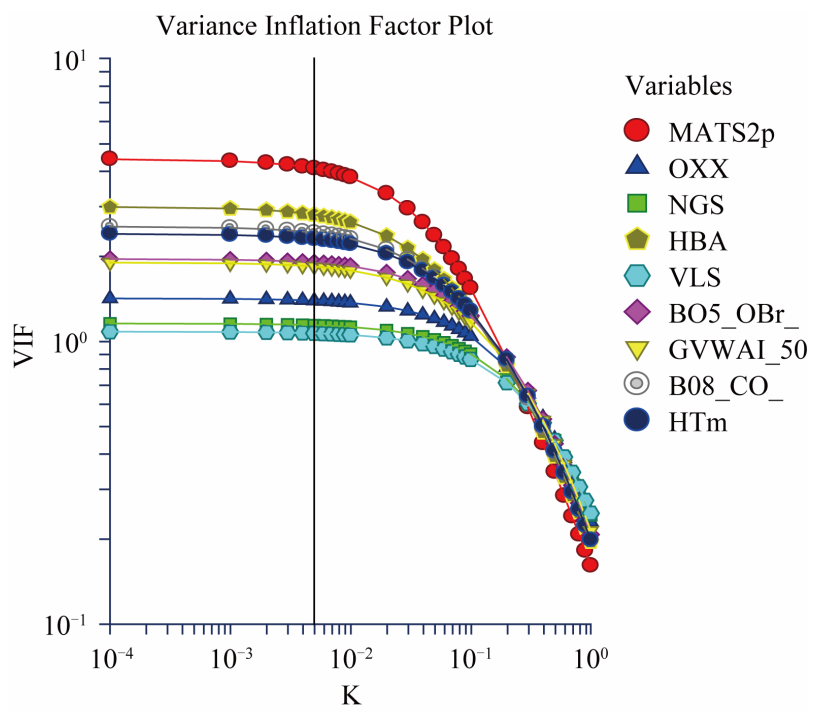

Figure 4. Ridge plot.

\section{Conclusions}

From the results and discussion made above we conclude that the PRECLAV software generates and proposes the overall best model and that there is no need of performing successive or stepwise regression to arrive at the best model. Such regressions are needed in NCSS software for obtaining the best model. Furthermore, while using PRECLAV software there is no need to perform model validation separately. Finally, PRECLAV software proposes virtual fragment which increases or decreases the biological activity. From the comparison made above we conclude that the PRECLAV software is the best for future 2D-QSAR study.

\section{Acknowledgements}

One of the authors (Shalini Singh) is thankful to DST (Department of Science and Technology) New Delhi for the project grant and to the authorities of Bareily College, Bareily-243001, UP, India for providing the facilities to carryout this work. And (Bashirulla Shaik) is thankful to Head, Department of Applied Sciences, NITTTR, Bhopal for providing the Research facilities.

\section{REFERENCES}

[1] M. Karelson, "Molecular Descriptor in QSAR/QSPR," John Wiley \& Sons, New York, 2000.

[2] PRECLAV software is purchased from Center of Organic Chemistry (CCO)-Bucharest, Romanian Academy, Petru Filip, pfilip@cco.ro.

[3] A. R. Katritzky, R. Petrukhin, S. Perumal, M. Karelson, I. Prakash and N. Desai, "A QSPR Study of Sweetness Potency Using the CODESSA Program," Croatica Chemica Acta, Vol. 75, No. 2, 2002, pp. 475-502.

[4] J. Devillers and A. T. Balaban, "Topological Indices and Related Descriptors in QSAR and QSPR," Gordon \& Breach Science Publishers, Amsterdam, 1999.

[5] M. Marder, H. Viola, J. A. Bacigaluppo, M. I. Colombo, C. Wasowski, C. Wolfman, J. H. Medina, E. Ruveda and A. C. Paladini, "Detection of Benzodiazepine Receptor Ligands in Small Libraries of Flavone Derivatives Synthesized by Solution Phase Combinatorial Chemistry," Biochemical and Biophysical Research Communications, Vol. 249, No. 2, 1998, pp. 481-485. doi:10.1006/bbrc.1998.9146

[6] K. Dekermendjian, P. Kahnberg, M. R. Witt, O. Sterner, M. Nielsen and T. Liljefors, "The Use of a Pharmacophore Model For Identification of Novel Ligands for The Benzodiazepine Binding Site of the $\mathrm{GABA}_{\mathrm{A}}$ Receptor," Journal of Medicinal Chemistry, Vol. 42, No. 21, 1999, pp. 4343-4350. doi:10.1021/jm991010h

[7] X. Hong and A. J. Hopffinger, "3D-Pharmacophores of Flavonoid Binding at the Benzodiazepine $\mathrm{GABA}_{\mathrm{A}} \mathrm{Re}$ ceptor Site Using 4D-QSAR Analysis," Journal of Che- 
mical Information and Modeling, Vol. 43, No. 1, 2003, pp. 324-326. doi:10.1021/ci0200321

[8] X. Huang, T. Liu, J. Gu, X. Luo, R. Ji, Y. Cao, H. Xue, J. T. Wong, B. L.Wong, G. Pei, H. Jiang and K Chen, "3DQSAR Model of Flavonoids Binding at Benzodiazepine Site in $\mathrm{GABA}_{\mathrm{A}}$ Receptors," Journal of Medicinal Chemistry, Vol. 44, No. 12, 2001, pp. 1883-1891. doi:10.1021/jm000557p

[9] P. Kahnberg, E. Lager, C. Rosenberg, J. Schougaard, L. Camet, O. Sterner, E. Ostergaard Nielsen, M. Nielsen and T. Liljefors, "Refinement and Evaluation of a Pharmacophore Model for Flavone Derivatives Binding to the Benzodiazepine Site of the GABA $\mathrm{A}$ Receptor," Journal of Medicinal Chemistry, Vol. 45, No. 19, 2002, pp. 41884201. doi:10.1021/jm020839k

[10] A. Da Settimo, G. Primofiore, F. Da Settimo, A. M. Marini, E. Novellino, G. Greco, C. Martini, G. Giannaccini and A. Lucacchini, "Synthesis, Structure-Activity Relationships, and Molecular Modeling Studies of $N$-(Indol-3-ylglyoxylyl)benzylamine Derivatives Acting at the Benzodiazepine Receptor," Journal of Medicinal Chemistry, Vol. 39, No. 26, 1996, pp. 5083-5091. doi:10.1021/jm960240i

[11] T. Blair and G. A. Webb, "Electronic Factors in the Structure-Activity Relations of Some 1,4-Benzodiazepin-2ones," Journal of Medicinal Chemistry, Vol. 20, No. 9, 1977, pp. 1206-1210. doi:10.1021/jm00219a019

[12] G. Greco, E. Novellino, C. Silipo and A. Vittoria, "Study of Benzodiazepines Receptor Sites Using a Combined QSAR-CoMFA Approach," Quantitative Structure-Activity Relationships, Vol. 11, No. 4, 1992, pp. 461-477. doi:10.1002/qsar.2660110403

[13] S. P. Gupta and A. Paleti, "Quantitative Structure-Activity Relationship Studies on Benzodiazepine Receptor Binding of Some Nonbenzodiazepine Series of Ligands," Quantitative Structure-Activity Relationships, Vol. 15, No. 1, 1996, pp. 12-16. doi:10.1002/qsar.19960150104

[14] P. R. Duchowicz, Ma. G. Vitale, E. A. Castro, J. C. Autino, G. P. Romanelli and D. O. Bennardi, "QSAR
Modeling of the Interaction of Flavonoids with GABA (A) Receptor," European Journal of Medicinal Chemistry, Vol. 43, No. 8, 2008, pp. 1593-1602. doi:10.1016/j.ejmech.2007.11.009

[15] DRAGON Software for calculation of topological indices. www.disat.unimib.it

[16] H. Kubinyi, "Variable Selection in QSAR Studies. II. A Highly Efficient Combination of Systematic Search and Evolution," Quantitative Structure Activity Relationships, Vol. 13, No. 4, 1994, pp. 393-401. doi:10.1002/qsar.19940130403

[17] R. D. Cramer, D. E. Patterson and J. D. Bunce, "Comparative Molecular Field Analysis (COMFA). 1. Effect of Shape on Binding of Steroids to Carrier Proteins," Journal of American Chemical Society, Vol. 110, No. 18, 1988, pp. 5959-5967. doi:10.1021/ja00226a005

[18] D. Chappel, “Trouble with CORBA," 1998. www.davidchappel.com. http://www.davidchappell.com/articles/article_Trouble_C ORBA.html

[19] OASIS. http://www.oasissolutionsllc.com/custom.html

[20] A. R. Katritzky, M. Karelson and R. Petrukhin, "Comprehensive Descriptors for Structural and Statistical Analysis". http://www.codessa-pro.com/index.html

[21] A. Kovatcheva, G. Buchbauer and A. Golbraikh, "QSAR Modeling of Alpha-Campholenic Derivatives with Sandalwood Odour," Journal of Chemical Information and Computational Science, Vol. 43, No. 1, 2003, pp. 259-266. doi:10.1021/ci020296n

[22] Hyperchem Molecular Modeling Software. www.hyper.com

[23] M. J. S. Dewar and H. S. Rzepa, "Ground States of Molecules. MNDO Results for Molecules Containing Beryllium," Journal of American Chemical Society, Vol. 100, No. 3, 1978, pp. 777-784. doi:10.1021/ja00471a020

[24] NCSS Statistical Analysis Software. www.ncss.com 